\title{
Student achievement goals and psychosomatic health complaints among Swedish adolescents: the role of sex
}

\author{
Daniel Bergh $^{1}$ (D) Joanna Giota ${ }^{2}$
}

Received: 6 March 2020 / Accepted: 22 July 2020 / Published online: 9 August 2020

(C) The Author(s) 2020

\begin{abstract}
Aim School related determinants (e.g. student motivation and goals) may be important for student achievement as well as their mental health. Therefore, the aim of this study was to analyse the links between two goal orientations (mastery and performance) and psychosomatic health problems by investigating the general patterns as well as the patterns for specific classifications of students, in particular by investigating the potential statistical interaction effects by gender.

Subject and methods Swedish nationally representative data among 4573 school year 9 students (15-16 years old) responding to the Evaluation Through Follow-up (ETF) questionnaire, in 2014, were used. Linear regression analysis as well as multinomial logistic regression were applied in order to address the research questions.

Results Both the mastery orientation and the performance orientation are independently associated with adolescent psychosomatic health problems. The links between these goal orientations and psychosomatic health show different patterns. The mastery goal orientation may be considered a protective factor as there is a negative link to psychosomatic problems; the performance orientation may be considered a risk factor due to the positive association with psychosomatic health problems. The effect of performance orientation on psychosomatic health complaints was significantly stronger for girls $(\mathrm{OR}=4.28)$ compared to boys $(\mathrm{OR}=2.04)$. In particular, low mastery/high performance students may be at risk for experiencing poor psychosomatic health. Conclusion Adolescent psychosomatic health may be improved by the encouragement of student goals related to adaptive and successful goal profiles such as mastery orientation.
\end{abstract}

Keywords Psychosomatic problems $\cdot$ Mental health $\cdot$ Student motivation $\cdot$ Goal orientations $\cdot$ Adolescents

\section{Introduction}

During the past few decades, self-reported mental health problems among Swedish adolescents have increased (Hagquist et al. 2019). In particular, this regards adolescents in later parts of compulsory school, when the students are aged 14-16 (Hagquist 2015). At this age, gender differences are also more pronounced, with girls reporting more mental health problems

Daniel Bergh

daniel.bergh@kau.se

Joanna Giota

joanna.giota@ped.gu.se

1 Centre for Research on Child and Adolescent Mental Health, Karlstad University, SE-651 88 Karlstad, Sweden

2 Department of Education and Special Education, University of Gothenburg, Box 300, SE-405 30 Gothenburg, Sweden compared to boys (Hagquist 2009). The pattern with increasing mental health problems among adolescents in Sweden, particularly among girls, seems to be similar to many western countries (Bor et al. 2014). The deteriorating mental health problems imply difficulties not only for individuals' psychological, social and educational development, but it also increases the burdens at the societal level (Potrebny et al. 2017). Early experiences of self-reported mental health problems are, further, connected to psychiatric disease and premature mortality (Ringbäck Weitoft and Rosén 2005), and having a diagnosed depression or anxiety at young age implies higher risks for psychiatric care later in life (Socialstyrelsen 2017). In addition, mental health symptoms often co-occur with somatic symptoms, and they are highly correlated (Dey et al. 2015). There is also increasing evidence suggesting that somatic health complaints in combination with mental health complaints are central aspects of mental disorders (van Geelen and Hagquist 2016). Therefore, mental health complaints and somatic complaints are considered to form a common 
composite measure of psychosomatic health on theoretical and empirical grounds (Potrebny et al. 2017), as is so in this study.

However, it may be hard to identify one single cause responsible for the increased levels of mental ill-health among young people. Raised hypotheses addressing the gender differences propose, for instance, that girls are subjected to more drastic physical puberty changes, greater perceived social demands, inconsistent role expectations and more frequent schoolrelated stresses and strains (Giota and Gustafsson 2017), which is in line with research suggesting that increased pressures related to the school context may be one explanation to the deterioration of adolescent mental health (Bor et al. 2014). For instance, in a recent study, increased school demands and stress between grade 6 and grade 9 , accounted for a substantial proportion of the increased gender differences in psychosomatic and depressive symptoms among Swedish students (Giota and Gustafsson 2017). In the research, several school related factors or key determinants of crucial importance for promoting mental health as well as academic success have been identified (Huang 2012). In fact, there is a reciprocal causal association between mental health and school achievement (Gustafsson et al. 2010), implying that improvements of mental health lead to improvements also of school achievement, and vice versa. Therefore, successful strategies for improvement of school achievement, most likely, also have a positive influence on student mental health (Gustafsson et al. 2010).

One of the most central among determinants for academic achievement is motivation. Achievement goals, within the Achievement Goal Theory perspective, are the most important components in studies on student motivation. Achievement goals reflect the various reasons or purposes students have for engaging in learning activities. Research generally report girls to have stronger goal orientations compared to boys, and students from families with higher education also have stronger orientations compared to those from families with lower education (Giota and Bergh 2020). These achievement goals are also of significant importance for student achievement (Schunk et al. 2008).

Traditionally, two different academic goals have been the focus for much of the research within this field: mastery goals (sometimes also called learning or task goals) and performance goals (sometimes called ego goals) (Dweck 1986). Students with a mastery goal orientation engage in learning activities in order to develop new skills, improving their competence and understanding (Elliot 1999, 2005). In that sense students adopting a mastery orientation may be considered as growth seeking (Dykman 1998). Thus, for mastery oriented students, how to learn and handle a task is important rather than the individual's standing relative to other students (Lee et al. 2010). For students adopting a performance goal orientation, the focus is on the ability relative to other students. For performance oriented students, ability is shown by outperforming other students, which makes social comparison a central component. For performance oriented students, it is important to gain public recognition and to meet external standards (e.g. high grades/marks) (Elliot 2005; Kaplan and Maehr 1999). Therefore, performance orientation can be considered as validation seeking (Dykman 1998).

There is a growing number of studies indicating that student goal orientations may be influential not only on achievement but also on adolescent well-being and mental health. Some studies indicate that different goal orientations may trigger different cognitive, behavioural and coping processes strongly related to adolescent health and well-being (Dykman 1998; King 2017). The research show that growth seeking (mastery) orientations are positively associated with subjective wellbeing (Tian et al. 2017; Yi et al. 2019), while validation seeking (performance) tend to show negative associations, in general (Sideridis 2005; Tuominen-Soini et al. 2008).

Given the parallel negative trends of mental health and school achievement, and their reciprocal causal association (Gustafsson et al. 2010), this is an area of great potential to improve both the mental health and school achievement of adolescents. However, much of the research in this field have been focused on the link between goal orientations and general well-being rather than on student mental and psychosomatic health. As far as we know, no other study has used psychosomatic health complaints among adolescents as an outcome variable addressing this research topic. In addition, relatively small samples using a correlational approach have been adopted. However, it is important to recognize that the associations may differ between different classifications of adolescents in order to facilitate effective health promoting interventions, which is rarely done. In particular, given that adolescent mental health differ by gender, and that student achievement show different patterns for boys and girls (OECD 2019), but also that boys and girls seems to differ with respect to goal orienations (Giota and Bergh 2020), it is reasonable to hypothesize that the link between goal orientations and psychosomatic health may differ by gender. This would, potentially, also have strong implications for health promotion.

Therefore, the aim of this study was to analyse the links between two goal orientations (mastery and performance) and psychosomatic health problems by investigating the general patterns as well as the patterns for specific classifications of students, in particular by investigating the potential statistical interaction effects by gender.

\section{Methods}

This study is based on data from the Swedish longitudinal ETF project (Evaluation Through Follow-up). In particular, the cohort of students born in 1998 and collected in 2014 
(aged 16) is used. The ETF study is conducted in close collaboration with Statistics Sweden since 1961, when the study first was initiated. In the ETF study, data is collected in the Swedish compulsory School (in grade 6, and in some cohorts also in grade 3 and 9), and in upper-secondary school (mostly in grade 12) (Svensson 2011). Thus, Statistics Sweden sampled all students in the present study when they attended grade 3. The sample size of each student cohort is about $10 \%$ of the total age cohort. These students have been followed up from 6th to 9th grade. The 1998 cohort consisted of 9549 students. Of these, in total 4573 students responded to the questionnaire in grade 9 , implying a response rate of about $48 \%$. The attrition rate for this cohort may cause concern and a reason for particular caution. However, analyses within the ETF-project show that the application of calibration weights calculated by Statistics Sweden removes most of the bias associated with systematic non-responses in the different ETF surveys in grade 9 (Giota and Gustafsson 2017). In addition to survey data, test and administrative data, as well as register data is added throughout the life span. The ETF survey data may be available upon request from the following address: https:/ips. gu.se/english/research/research_projects/ETF

\section{Instruments}

\section{Psychosomatic health complaints}

Psychological complaints and somatic health complaints often co-occur and are highly correlated among adolescents, and they are also considered to form a unidimensional construct (Potrebny et al. 2017). In this study, the PsychoSomatic Problems (PSP) scale was used as an outcome measure (Hagquist 2008). The PSP scale comprises eight items intended to capture information about psychosomatic health problems among children and adolescents in general populations. The PSP scale is constructed by the summation of pupils' responses across the following eight items: (1) had difficulty in concentrating, (2) had difficulty in sleeping, (3) suffered from headaches, (4) suffered from stomach aches, (5) felt tense, (6) had little appetite, (7) felt sad, (8) felt giddy, using the following response format: (a) Never, (b) Seldom, (c) Sometimes, (d) Often, and (e) Always. The PSP scale shares many similarities with the HBSC-SCL scale on psychosomatic symptoms, which has been widely spread and used internationally for decades. While the content of the items are similar in the PSP scale and the HBSC scale, the construction of the response categories are different. The qualitative format used in the PSP scale has been shown to work better than the quantitative format used in the HBSC-SCL scale (Andrich 2004; Hagquist 2008). In this study, psychosomatic problems are used as a generic concept tapping psychological and somatic complaints, and without making any presumptions about aetiology, which is in line with other studies addressing psychosomatic health among children and adolescents using the PSP and HBSC-SCL scales (Barkmann et al. 2015; Hagquist 2016).

\section{Student questionnaire responses on goal orientations}

The goal orientations reflect different purposes or reasons for students to engage in learning activities, but student with different goal orientations also define academic success differently. The achievement goal orientation items intended to measure Mastery and performance, included in the ETF survey was used. The items were developed in 2004 within ETF based on previous research by Author (Giota 2010; Giota and Bergh 2020), and somewhat modified items from the Patterns of Adaptive Learning Surey (PALS) (Midgley et al. 1997).

Mastery goal orientation The mastery goal orientation is described as 'learning goals' characterized by students trying to increase their competence and understanding, as well as to learn new things. Thus, the mastery orientation reflects a desire to develop competence by learning as much as possible. Therefore, mastery oriented students engage in learning activities in order to attain understanding, academic competence and ability relative to self-established standards (Senko 2016). In this study, the following items where used in order to measure mastery goal orientation: How often are you trying to do the following in school: (1) Learn to be smarter, (2) Learn new things, (3) Learn to understand better, (4) Learn facts. The following response format applied: (a) Always/Almost Always, (b) Often, (c) Sometimes, (d) Rarely, (e) Never/ Almost Never. A composite measure of mastery goal orientation was formed by the summation of persons responses across items. From an educational approach, mastery orientation has been considered as adaptive motivation stimulating challenge seeking, efforts as well as successful learning and related outcomes.

Performance goal orientation The performance goal orientation is described as achievement in order to attain favourable evaluations of one's own competence or ability, but also to avoid unfavourable evaluations. Performance goals are characterized by a desire to demonstrate existing competence or ability by outperforming peers. Performance oriented students define success relative to external standards such as rankings (Senko 2016). In this study, the following items were used in order to measure performance goal orientation: How often are you trying to do the following in school: (1) To be better than other pupils in the class, (2) Show my teacher that I am smarter than other pupils, and (3) Learn so that I will not appear stupid in front of others. The following response format applied: (a) Always/Almost Always, (b) Often, (c) Sometimes, (d) Rarely, (e) Never/Almost Never. A composite measure of performance goal orientation was formed by the 
summation of persons responses across items. Since performance goals are not considered to stimulate challenge seeking, efforts or successful learning to the same extent as mastery goals, performance goals have been considered as maladaptive motivation.

\section{Register data}

Student achievement In the Swedish comprehensive school, grades are based on curriculum goals and subject guidelines that students are expected to achieve in school year 9. Students born in 1998 have received grades from year 6 and onwards. The average merit rating is the summation of the 17 best subjects, implying a total score of 340 , using the following scoring $(\mathrm{A}=20, \mathrm{~B}=17.5, \mathrm{C}=15, \mathrm{D}=12.5, \mathrm{E}=10$, and $\mathrm{F}=0)$.

Parental education In this study, register data on parental education, provided by Statistics Sweden, was used as an important background variable. The measure provided includes three levels of the family's highest education: Elementary education, Upper-Secondary school, and Higher education. This variable was recoded using dummy coding into the categories: (0) Higher education, and (1) at most upper-secondary school, for the linear regression analyses.

\section{Data analysis}

\section{Psychometric analyses}

The psychometric properties of the PSP scale as well as the composite measures of goal orientations were analysed by using the polytomous Rasch Model (Rasch 1960/1980). Since the property of invariance of measurement comprises an integral part of the Rasch model, it is possible to test if the items work invariantly across different classifications of individuals that are to be compared statistically (Andrich 1988). This means that if the data conform to the Rasch model, the use of person measures based on the summation of raw scores across items is justified. For introductory presentations of the application of the Rasch model within health sciences see Hagquist et al. (2009). Given that the data fit the model, analysis within the Rasch framework transforms the non-linear raw scores to person values on a linear interval (equidistant) logit scale, suitable for parametric statistical analysis. These logit scales of PSP, mastery and performance (ranging from approximately -4 to 4 logits) were used in the statistical analysis. For the PSP scale, a low logit score indicate few or only mild psychosomatic problems, whereas a high logit value translates to more or more severe problems. In the mastery and performance scales, a low logit value implies weak orientation, while a higher value translates to strong goal orientation. All psychometric analyses were conducted using the RUMM2030 software (Andrich et al. 2013).

\section{Regression analyses}

The link between goal orientations and psychosomatic problems was initially analysed using linear regression analysis. Thus, the composite measures on goal orientation were entered as independent variables, and the PSP scale as dependent variable. In order to find out whether the associations are similar for different subgroups of individuals, the influence of formal interaction terms were tested. All linear regression analyses were conducted using R (version 3.5.3). In addition, the 'effects' package (Fox et al. 2019) was used for graphical representations of the interaction terms investigated (not included in this paper).

In order to be able to contrast students with many or relatively severe psychosomatic health problems with those with few or only mild problems, the PSP scale was trichotomized using the percentile values. Thus, students located within the lower 10 percentiles of the PSP scale formed the 10 percentiles category, the 11-89 span formed a middle category, whereas the students located within the 90-100 percentile span represents the 90 percentile category. In addition, the mastery and performance measures were dichotomized by using their percentile values. Thus, along the mastery measure, persons located within the lower 50\% span formed the category low mastery, and persons located in the upper 50\% span formed the category high mastery. Using the same rationale, the categories low performance, and high performance was constructed. These variables were subjected to multinomial logistic regression analysis entering the trichotomized PSP scale as dependent variable and the dichotomized mastery and performance scales as independent variables. All table analyses were conducted using the SPSS 26 software.

In order to further clarify the patterns observed, a typology combining the mastery and performance measures was constructed. This combination variable was entered into a multinomial logistic regression analysis contrasting the high mastery/low performance combination category to other combination categories of this variable. The high mastery/low performance combination was set as reference in the analysis because that is the combination where least psychosomatic problems are expected to be found. The analysis is presented graphically, divided by sex.

\section{Results}

\section{Sample characteristics}

Out of the 4573 students responding to the 2014 questionnaire, $51 \%$ were boys and $49 \%$ girls. Most of the students where aged $16(96 \%)$ at the year of data collection, and only a small proportion where younger ( $2 \%$ aged 15$)$ or older $(2 \%$ aged 17). Regarding parental education, the following 
proportions applied: elementary school $9 \%$, upper-secondary school $44 \%$, and higher education $47 \%$. The mean average merit rating (student achievement with maximum score of 340 ) for the sample group is $240.9(\mathrm{SD}=50.3)$. The achievement of girls $(249.6 ; \mathrm{SD}=49.7)$ is somewhat higher compared to that of boys $(230.1 ; \mathrm{SD}=48.9)$. Student achievement varies with respect to parental education. Thus, the average merit rating for students from families with elementary school as the highest education $(205.5 ; \mathrm{SD}=56.5)$ is lower than for students from families with upper-secondary school (224.4; $\mathrm{SD}=51.5$ ), followed by that of students from higher education families $(255.8 ; \mathrm{SD}=43.1)$ (results not presented in a table).

\section{Psychometric analyses}

In Table 1, the distribution in the response categories of the individual items used in order to construct the Psychosomatic Problems (PSP) scale is displayed. The general pattern implies smaller proportions in the always category and larger proportions in the seldom or sometimes categories. In particular, the items "Felt giddy" and "Little appetite" show large proportions in the never category compared to other items. Table 2 gives the distribution into response categories in the goal orientation measures. Regarding the mastery goal orientation scale, smaller proportions can be observed in the never/ almost never category, and larger proportions in the always/ almost always, often or sometimes categories. In the performance goal orientation measure, the response pattern is different. For instance, a larger proportion of responses fall into the categories sometimes, rarely or never/almost never, and a smaller proportion in the always/almost always category.

The psychometric analysis of the PSP has previously shown good fit to the Rasch model with high reliability, invariance of measurement and proper empirical categorization, reflecting one common dimension (Hagquist 2008), as is also so in this study (Cronbarch's Alpha analogous Person Separation Index, PSI = .85). Thus, on the basis of these analyses, it was concluded and confirmed that the somatic and psychological complaints included in the composite measure form one single dimension. Thus, on the basis of these analyses, it was the correct decision to consider somatic and psychological complaints to form a higher order unidimensional construct. It was also shown that items included, as a whole, worked well together, but that one item showed problematic differential item functioning (DIF) by gender, i.e. it worked differently for boys and girls. This regarded the item 'Felt sad'. However, this sort of lack of invariance has been addressed by equating, in order to be able to appropriately compare boys and girls along the composite measure. Thus, the item 'Felt sad' was resolved by gender, forming a gender specific item. After this procedure the, the PSP scale conformed to the Rasch model, implying that the items used describe one common theoretical construct working invariantly also across gender.

The Rasch analysis of the composite measure of mastery show that the data as a whole fit the Rasch model in an acceptable way. The Cronbach's alpha analogous, the Person Separation Index (PSI), is relatively high given that only four items are included in the measure (.79). The precision of measurement may be improved by the inclusion of additional items of appropriate severity. However, separate items work well together. In particular the items 'Learn to be smarter' and 'Learn new things' work well together, whereas item 'Learn facts' and 'Learn to understand better' showed only mild deviations from the Rasch model. In addition, there are no problematic differential item functioning (DIF) across genders. However, two items show uniform (consistent) DIF. Thus, in the item 'Learn facts', boys consistently score higher than girls, and in the item 'Learn to understand better', girls consistently score higher than boys. The composite measures also meet the criterion of proper empirical ordering of the data, there are no reversed item thresholds, meaning that the response categories work as intended.

The Rasch analysis of the composite measure of performance show that the data as a whole fit the the Rasch model in an acceptable way. However, given that the performance
Table 1 The distribution in the response categories in the separate items included in the Psychosomatic Problems (PSP) scale. Percent (n), the 1998 cohort of the ETF study

\begin{tabular}{llllll}
\hline & Never & Seldom & Sometimes & Often & Always \\
\hline Psychosomatic problems & & & & & \\
Difficulty concentrating & $8.4(375)$ & $28.4(1260)$ & $38.2(1694)$ & $19.9(885)$ & $5.1(226)$ \\
Difficulty sleeping & $17.2(764)$ & $31.7(1409)$ & $29.4(1304)$ & $16.3(723)$ & $5.4(240)$ \\
Headaches & $17.7(784)$ & $34.0(1508)$ & $27.2(1208)$ & $16.6(736)$ & $4.6(204)$ \\
Stomachaches & $25.0(1110)$ & $36.3(1613)$ & $23.4(1040)$ & $12.3(544)$ & $3.0(133)$ \\
Felt tense & $15.3(681)$ & $29.3(1300)$ & $29.8(1325)$ & $19.8(881)$ & $5.7(253)$ \\
Little appetite & $37.8(1678)$ & $32.9(1459)$ & $18.6(827)$ & $7.9(352)$ & $2.8(124)$ \\
Felt sad & $16.4(727)$ & $34.4(1528)$ & $28.4(1261)$ & $16.0(711)$ & $4.8(213)$ \\
Felt giddy & $32.4(1440)$ & $34.3(1524)$ & $20.7(918)$ & $10.3(458)$ & $2.3(100)$ \\
\hline
\end{tabular}


Table 2 The distribution in the response categories in the separate items included in the mastery and performance measures. Percent (n), the 1998 cohort of the ETF study

\begin{tabular}{|c|c|c|c|c|c|}
\hline & Always/almost always & Often & Sometimes & Rarely & Never/almost never \\
\hline \multicolumn{6}{|l|}{ Mastery } \\
\hline Learn to be smarter & $24.4(1109)$ & $38.8(1759)$ & $24.2(1097)$ & $9.3(421)$ & $3.3(152)$ \\
\hline Learn facts & $18.4(834)$ & $38.9(1763$ & $31.9(1447)$ & $8.6(391)$ & $2.2(100)$ \\
\hline Learn to understand & $30.9(1397)$ & $42.7(1933)$ & $20.8(941)$ & 4.4 (197) & $1.3(57)$ \\
\hline Learn new things & $31.3(1419)$ & $42.2(1912)$ & $21.6(982)$ & $3.9(177)$ & $1.0(46)$ \\
\hline \multicolumn{6}{|l|}{ Performance } \\
\hline Be better than others & $10.8(489)$ & $18.7(847)$ & $29.4(1333)$ & $26.5(1203)$ & $14.6(661)$ \\
\hline Not appear stupid & $9.7(441)$ & $17.3(783)$ & $23.8(1077)$ & $26.7(1207)$ & $22.5(1021)$ \\
\hline Show teacher & $7.1(320)$ & $10.6(482)$ & $20.4(923)$ & $30.1(1363)$ & $31.8(1440)$ \\
\hline
\end{tabular}

measure consists of only three items, it is reasonable that the measure show lower reliability (.71). Owing to the very few items included in the composite measure, the precision of measurement may be improved by the inclusion of additional items of appropriate severity. The separate items work relatively well together. In particular, the item 'To do better than other pupils in the class' and the item 'Learn so that I will not appear stupid in front of others' work well together. However, the item 'Show my teacher that I am smarter than other pupils' reveal some mild deviations to the model. Students with weak performance orientation tend to score somewhat lower than expected by the Rasch model on this particular item. Regarding DIF, no problematic DIF-effects can be observed. However, girls tend to consistently score higher on the item 'Learn so that I will not appear stupid in front of others', whereas boys tend to score consistently higher on the item 'Show my teacher that I am smarter than other pupils'. The composite measures also meet the criterion of proper empirical ordering of the data, there are no reversed item thresholds, meaning that the response categories work as intended.

\section{Regression analyses of goal orientation and psychosomatic health complaints}

The association between goal orientations (mastery and performance) and psychosomatic health complaints (PSP) was initially analysed using linear regression analysis. Table 3 shows the regression analysis with the goal orientation scales entered as independent variables, in separate models, and the PSP scale as dependent variable, and with adjustments for sex, parental educational level, and student achievement. From Table 3 it can be seen that girls report more psychosomatic problems compared to boys, and that students from families with lower education report more psychosomatic problems compared to those from families with higher education, and that student achievement is negatively related to psychosomatic ill-health. However, when student achievement is also included in the model, the effect of parental educational level turns non-significant. It is also evident that there is a strong association between goal orientations and psychosomatic health complaints. For instance, for each logit increase along the mastery goal orientation scale, a 0.11 logit decrease applies along the PSP scale, on average (model A). Thus, there is a negative association between mastery and psychosomatic problems. However, this pattern is different when it comes to the performance goal orientation. Instead of showing a negative association, the performance goal orientation shows a positive association with psychosomatic problems. Thus, for each logit increase along the performance goal orientation, a 0.10 logit increase of psychosomatic problems applies, on average (model B). When analysed simultaneously there is a slight increase of the effect of goal orientation on psychosomatic problems (model C). When also taking into account the influence of student achievement, the effect of mastery orientation is decreasing, but the effect of performance orientation increases (model D). From Table 3, it is also evident that the link between performance orientation and psychosomatic problems is modified by sex as the statistical interaction term sex*performance was significant. This implies that for each logit increase along the performance goal orientation measure, the effect on psychosomatic problems is stronger for girls compared to boys. Consequently, for each logit increase along the performance orientation scale, there is a 0.20 logit increase among girls and a 0.11 logit increase among boys, on average (model E).

In order to contrast students experiencing relatively severe psychosomatic health problems with those experiencing only mild problems, the dichotomized mastery and performance measures were subjected to multinomial logistic regression analysis, which is shown in Table 4 . These results show that low mastery students are more than twice as likely to experience severe psychosomatic problems compared to high mastery students (model A). The opposite pattern can be observed regarding the performance measure (model B) 


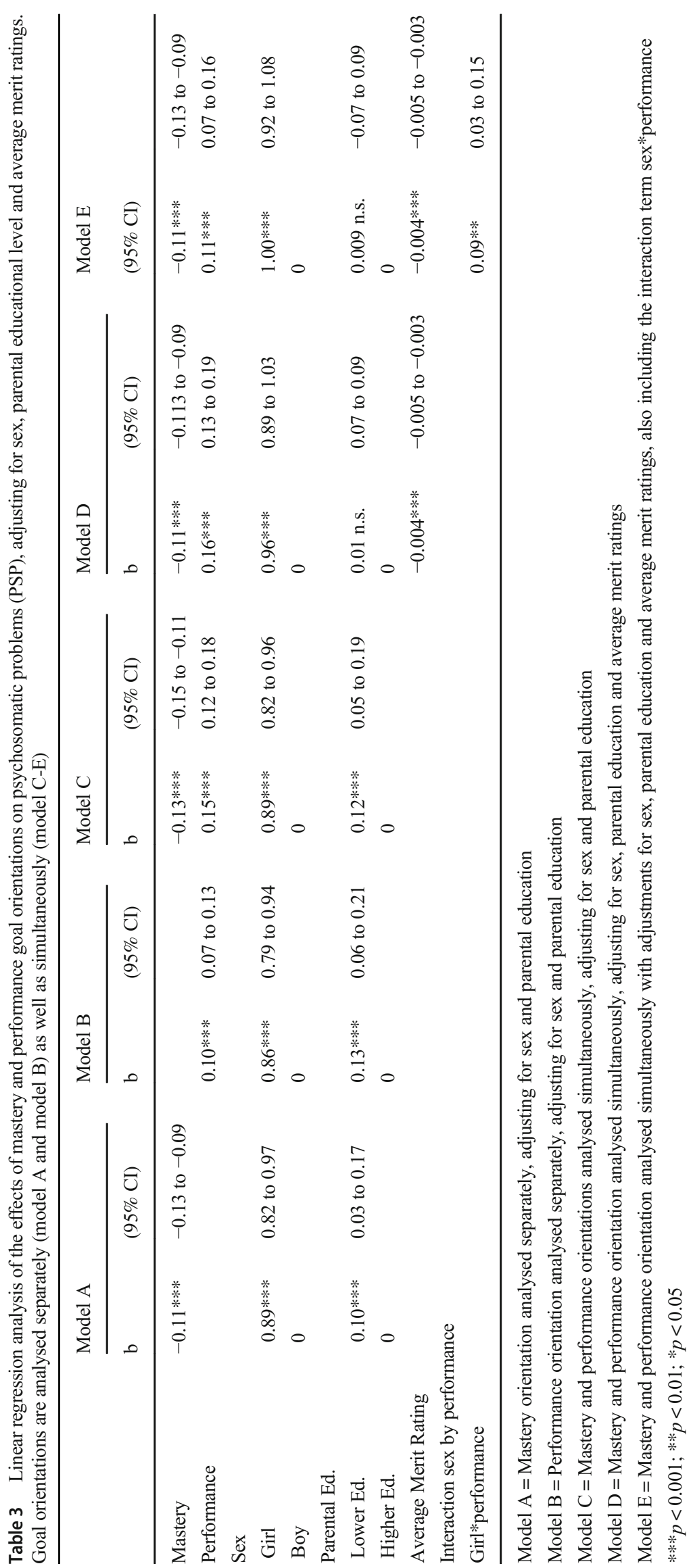


Table 4 Multinomial logistic regression of psychosomatic health complaints (percentile 10 versus percentile 90 ), with adjustments for sex and parental educational level

\begin{tabular}{|c|c|c|c|}
\hline Variables & $\begin{array}{l}\text { Model A } \\
\text { OR } \\
(95 \% \mathrm{CI})\end{array}$ & $\begin{array}{l}\text { Model B } \\
\text { OR } \\
(95 \% \mathrm{CI})\end{array}$ & $\begin{array}{l}\text { Model C } \\
\text { OR } \\
(95 \% \mathrm{CI})\end{array}$ \\
\hline \multicolumn{4}{|l|}{ Mastery } \\
\hline Low & $\begin{array}{l}2.12 * * * \\
(1.61-2.79)\end{array}$ & & $\begin{array}{l}2.51 * * * \\
(1.89-3.32)\end{array}$ \\
\hline High & 1 & & 1 \\
\hline \multicolumn{4}{|l|}{ Performance } \\
\hline High & & $\begin{array}{l}1.74 * * \\
(1.09-2.80)\end{array}$ & $\begin{array}{l}2.04 * * * \\
(1.27-3.29)\end{array}$ \\
\hline Low & & 1 & 1 \\
\hline \multicolumn{4}{|l|}{ Sex } \\
\hline Girl & $\begin{array}{l}16.30 * * * \\
(11.84-22.44)\end{array}$ & $\begin{array}{l}16.74 * * * \\
(12.14-23.09)\end{array}$ & $\begin{array}{l}11.68 * * * \\
(7.48-18.23)\end{array}$ \\
\hline Boy & 1 & 1 & 1 \\
\hline \multicolumn{4}{|l|}{ Parental education } \\
\hline Primary education & $\begin{array}{l}1.39 \text { n.s. } \\
(0.75-2.57)\end{array}$ & $\begin{array}{l}1.26 \text { n.s. } \\
(0.68-2.33)\end{array}$ & $\begin{array}{l}1.33 \text { n.s. } \\
(0.72-2.48)\end{array}$ \\
\hline Upper-secondary school & $\begin{array}{l}0.99 \text { n.s. } \\
(0.74-1.33)\end{array}$ & $\begin{array}{l}0.98 \text { n.s. } \\
(0.73-1.31)\end{array}$ & $\begin{array}{l}1.00 \text { n.s. } \\
(0.75-1.35)\end{array}$ \\
\hline Higher education & 1 & 1 & 1 \\
\hline Average merit rating & $\begin{array}{l}0.991 * * * * \\
(0.988-0.993)\end{array}$ & $\begin{array}{l}0.991 * * * \\
(0.988-0.993)\end{array}$ & $\begin{array}{l}0.990 * * * \\
(0.987-0.992)\end{array}$ \\
\hline & 1 & 1 & 1 \\
\hline Interaction term sex*performance & & $\begin{array}{l}2.20 * * \\
(1.16-4.14)\end{array}$ & $\begin{array}{l}2.10^{*} \\
(1.11-3.97)\end{array}$ \\
\hline
\end{tabular}

Model A = Mastery measure analysed separately

Model $\mathrm{B}=$ Performance measure analysed separately including the interaction term sex*performance

Model $\mathrm{C}=$ Mastery and performance measures analysed simultaneously, also including the interaction term sex*performance

$* * * p<0.001, * * p<0.01, * p<0.05, \mathrm{~ns}=$ non-significant showing high performance students to be about twice as likely to experience severe psychosomatic health problems compared to low performance students. However, the significant statistical interaction effect implies that the influence of performance on psychosomatic problems is stronger for girls (OR 3.83) compared to that of boys (OR 1.74). When the two measures are analysed, simultaneously the odds ratios are increased slightly (model C). Model C also reconfirms that the interaction effect (sex*performance) persists when also taking the mastery measure into account. The odds ratio for high performance boys is 2.04 , and the corresponding odds ratio among girls is 4.28. Table 4 also reconfirms that girls experience more psychosomatic health problems compared to boys and that student achievement is negatively linked to psychosomatic health. It also reconfirmes that the effect of parental educational level is taken out by the influence of student achievement.

In order to clarify the patterns observed, a typology was constructed by combining the mastery and performance dichotomous measures. The high mastery/low performance combination was contrasted to the other combinations, as this is the combination where fewer psychosomatic problems are expected to be found. This analysis is presented in Fig. 1.

In particular students in the low mastery/high performance combination experience severe psychosomatic problems to a higher extent compared to high mastery/low performance students. The resulting odds ratios corresponding to that comparison is 4.7 for boys and 14.4 for girls. The low mastery/high performance category is also where most influence of the sex by performance interaction effect can be observed, resulting in large differences between boys and girls. In all other combinations, boys and girls show similar odds ratios.

\section{Discussion}

The overall aim of this study was to analyse the links between student goal orientations and psychosomatic health 
Fig. 1 Odds ratios of experiencing severe psychosomatic problems (percentile 90 versus percentile 10) for different combinations of the dichotomized masteryperformance measures. Odds ratios are based on multinomial logistic regression analysis adjusting for parental educational level and average merit ratings and with division by sex, using the high mastery/low performance combination as reference



complaints. Given that achievement goals are associated with different ways students cope with success and failures in school, these goals may also be associated with adolescent psychosomatic health (Dykman 1998; Sideridis 2005).

The general patterns from the results also reveal that there are strong relationships between student goal orientations and psychosomatic health complaints. Overall, the results show the mastery orientation to be negatively associated with psychosomatic health complaints and the performance orientation to be positively associated with psychosomatic ill-health. Thus, increasing levels of mastery orientation corresponds to decreasing levels of psychosomatic health complaints. Consequently, mastery orientation may be considered a protective factor against adolescent psychosomtic ill-health. On the contrary, increasing levels of performance orientation instead corresponds to increasing levels of psychosomatic health complaints. Therefore, performance orientation may be considered a risk factor for adolescent psychosomatic illhealth. The results apply for the linear regression analyses as well as for the multinomial logistic regression analyses conducted.

These patterns are also consistent with hypotheses raised in previous research suggesting that that achievement goals related to growth and self-improvement (mastery) are positively related to student well-being and mental health (Tian et al. 2017; Tuominen-Soini et al. 2008; Yi et al. 2019), whereas goals related to validation seeking (performance) tend to be negatively related to well-being and mental health. Thus, considering the social comparison component of the performance orientation to be salient (Tian et al. 2017; Yi et al. 2019), it is reasonable to consider the outcome of that comparison a potential source of stress or anxiety. This component of performance goals may be influential on student self-esteem and general well-being as well as for the vulnerability for depression (Dykman 1998; Kaplan and Maehr 1999). While trying to outperform the peers, students may be successful or unsuccessful, and the consequence for unsuccessful students may be decreased self-esteem or other mental health related consequences, and potentially with increased vulnerability for depression (Sideridis 2005). In a comprehensive review (Gustafsson et al. 2010), it was also concluded that failing to keep up to the peers may be linked to internalizing mental health problems, which in turn may cause externalizing problems.

Previous research studies, where the dichotomous distinction between mastery and performance goals have been investigated, show that these goals, albeit correlated, to be distinct from each other also with respect to student outcomes (Ames and Archer 1988; Dowson and McInerney 2004), including mental health. In line with previous research, our results show these two types of achievement goals to be independently linked to psychosomatic health complaints. Thus, no statistically significant interaction effect could be observed between them. That is, the negative effect of mastery orientation on psychosomatic health was not influenced by the effect of the performance orientation, and the positive link between performance orientation and psychosomatic health problems was not dependent on the effect of the mastery orientation.

Moreover, we found the association between mastery and psychosomatic health to be similar for girls and boys. The link 
between performance orientation and psychosomatic health on the other hand did differ by sex. The association was stronger for girls compared to that for boys, which applies to the linear regression analysis as well as to the multinomial logistic regression analysis. Considering the social comparison component of the performance orientation as a potential source of stress, in particular if expectations of being successful in school are threatened, the stronger link to psychosomatic health for girls compared to boys is reasonable. For instance, it has been suggested that girls, in a Swedish school context, experience more negative aspects related to social interactions, performance and responsibility, and therefore are at greater risk for mental health problems (Landstedt et al. 2009). In a recent study, the increasing gender differences in mental health was suggested to be due to higher levels of stress and perceived school demands among girls (Giota and Gustafsson 2017). Given that girls experience more negative processes and more demands in school, and consider schoolwork more important than do boys, it is reasonable that they, from a psychosomatic health perspective, are more negatively influenced by having a strong performance orientation.

On the basis of previous studies suggesting mastery orientation to be negatively related to anxiety and depression, and performance oriented students to be more anxious compared to mastery students when facing demanding school tasks, a typology combining the mastery and performance measures was constructed. By subjecting this combination variable to multinomial logistic regression analysis, it was possible to identify groups that may be at particular risk for experiencing poor psychosomatic health. This was done by contrasting the high mastery/low performance category (where the least amount of psychosomatic health complaints are expected to be found) with other combinations. By doing this, the conclusion of the independent contribution of mastery and performance orientations on psychosomatic health was reasserted. The low mastery/high performance combination category was identified as the combination with the highest levels of psychosomatic health complaints. Thus, students within this category form a group that may be at particular risk to experience psychosomatic ill-health. This is also the combination with the largest differences between boys and girls.

The independent links between the mastery and performance goal orientations and psychosomatic health indicate that effort is needed in order to improve the psychosomatic health of groups of adolescents holding these orientations. Expressed differently: Adolescent well-being and health may be improved by encouraging students to adopt goals related to mastery orientation, which have been suggested in recent studies (Tian et al. 2017; Yi et al. 2019). In the same way, in order to prevent psychosomatic ill-health, especially among girls, it may also be reasonable to redirect students from goals central to performance orientations towards more persisting, adaptive and successful mastery goal profiles.

\section{Limitations}

The PSP scale used as an important outcome variable was available only for the cohort born in 1998 among school year 9 students. Therefore, it was not possible to take advantage of the longitudinal design of the ETF study. However, in subsequent cohorts of the ETF study, the PSP scale will be available, allowing for trend analysis. The data were collected in 2014 when the students attended school year 9 and were 16 years old. Given that some time has passed since the data collection took place, it may be reasonable to hypothesise that the data may not reflect the current adolescents' goal orienations and psychosomatic health. However, the Swedish school system has not undergone any substantial reforms likely to influence student goal orientations within the past six years. In addition, goal orientations have proved to be relatively stable over cohorts, as is shown by previous studies within the ETF-project (Giota and Bergh 2020). Also with respect to psychosomatic health, it is likely to reflect the current state among adolescents. In addition, according to large scale assessments, the achievement of Swedish school year 9 students is not significantly different in 2018 compared to 2015 (OECD 2019).

Developments within the goal orientation theory suggest a dichotomizaton of the performance measure into performance-approach and performance-avoidance parts. The performance-approach form is defined as achievement in order to attain favourable evaluations of one's own competence or ability. The performance-avoidance is instead defined as achievement in order to avoid unfavourable evaluations of ability (Elliot 1999; Elliot and Church 1997; Midgley et al. 1997). Given that only three performance items where included in the ETF study, it was not possible to bifurcate the performance measure into the approach and avoidance forms with maintained reliability. Instead, the psychometric analysis suggested one single composite measure. However, as pointed out by several scholars, it seems that the approach forms of mastery and performance goals paradoxically are those two goals whose effects are much of the debate within achievement goal theorists (Huang 2012; Senko 2016).

In addition, given the cross-sectional nature of the data, it is not possible to rule out whether the adolescents' psychosomatic health status is influenced by their motivational orientations, or whether they have a specific motivational orientation due to their psychosomatic health status. In order to examine the causal relationship, future cohorts of the ETF study will be helpful.

\section{Conclusion}

During the past few decades adolescent psychosomatic and mental health has deteriorated in many western countries. In 
Sweden, there has also been a parallel decrease in adolescent school achievements. The link between school achievements and mental health has been suggested to be causal, but reciprocal. Thus, efforts made in order to improve the academic achievement among students may not only improve achievement but also mental health, and strategies in order to improve the mental health of adolescents may also be beneficial for student achievement. Several determinants important for mental health as well as student achievement have been identified. In this study the link between student motivational goals (mastery and performance orientations) and psychosomatic health was investigated. Both mastery and performance orientations was independently linked to psychosomatic health problems. However, the mastery orientation showed a protective effect against psychosomatic ill-health whereas the performance orientation turned out to be a risk factor, in particular for girls. Thus, increased mastery orientations imply improved psychosomatic health, whereas increased performance orientation is related to worsened psychosomatic health, more so for girls compared to for boys. In particular, the combination of low mastery/ high performance students may be at risk for experiencing poor psychosomatic health. However, the independent links between mastery and performance orientations on psychosomatic health indicate that there effort is needed in order to improve the psychosomatic health among students holding these orientations. Adolescent psychosomatic health may be improved by the encouragement of student goals related to adaptive and successful goal profiles such as mastery orientation. Given that Swedish adolescents show negative trends in both mental health and school achievement, increased mastery orientation may be particularly beneficial from not only a public health perspective but also from an educational point of view. However, given the cross-sectional nature of the data it was not possible to rule out the direction of the associations. Therefore, future cohorts of the ETF-study are promising with respect to the possibility to examine the directions of the links.

Acknowledgements Open access funding provided by Karlstad University.

Authorship contribution statement The manuscript has been coauthored in close collaboration between the authors and they have both actively, and substantially contributed to this version of the manuscript.

\section{Compliance with ethical standards}

Ethics approval and consent to participate This study was drawn from a research project (VR dnr: 2014-47450-112501-64) funded by the Swedish Research Council.

Conflict of interest The authors declare that they have no conflict of interest.
Open Access This article is licensed under a Creative Commons Attribution 4.0 International License, which permits use, sharing, adaptation, distribution and reproduction in any medium or format, as long as you give appropriate credit to the original author(s) and the source, provide a link to the Creative Commons licence, and indicate if changes were made. The images or other third party material in this article are included in the article's Creative Commons licence, unless indicated otherwise in a credit line to the material. If material is not included in the article's Creative Commons licence and your intended use is not permitted by statutory regulation or exceeds the permitted use, you will need to obtain permission directly from the copyright holder. To view a copy of this licence, visit http://creativecommons.org/licenses/by/4.0/.

\section{References}

Ames C, Archer J (1988) Achievement goals in the classrool: Pupils' learning strategies and motivation processes. J Educ Psychol 80: 260-267

Andrich D (1988) Rasch models for measurement. Sage, Newbury Park

Andrich D (2004) Hagquist C detection of differential item functioning using analysis of variance. In: the second international conference on measurement in health. Developments with Rasch models. Murdoch University, Perth

Andrich D, Sheridan B, Luo G (2013) RUMM2030: a windows program for the Rasch unidimensional measurement model. RUMM Laboratory, Perth

Barkmann C, Otto C, Schön G, Schulte-Markwort M, Schlack R, Ravens-Sieberer U, Klasen F (2015) Modelling trajectories of psychosomatic health complaints in children and adolescents: results of the BELLA study. Eur Child Adolesc Psychiatry 24:685-694

Bor W, Dean A, Najman J, Hayatbakhsh R (2014) Are child and adolescent mental health problems increasing in the 21 st century? A systematic review. Aust N Z J Psychiatry 48:606-616

Dey M, Jorm AF, Mackinnon J (2015) Cross-sectional time trends in psychological and somatic health complaints among adolescents: a structural equation modelling analysis of 'Health behaviour in school-aged Children' data from Switzerland. Soc Psychiatry Psychiatr Epidemiol 50:1189-1198

Dowson M, McInerney DM (2004) The development and validation of the goal orientation and learning strategies survey (goals-S). Educ Psychol Meas 64:290-310. https://doi.org/10.1177/ 0013164403251335

Dweck CS (1986) Motivational processes affecting learning. Am Psychol 41:1040-1048. https://doi.org/10.1037/0003-066X.41.10.1040

Dykman BM (1998) Integrating cognitive and motivational factors in depression: initial tests of a goal-orienation approach. J Pers Soc Psychol 74:139-158

Elliot AJ (1999) Approach and avoidance motivation and achievement goals. Educ Psychol 34:169-189. https://doi.org/10.1207/ s15326985ep3403_3

Elliot AJ (2005) A conceptual history of the achievement goal construct. In: Handbook of competence and motivation. Guilford, New York, pp 52-72

Elliot AJ, Church MA (1997) A hierarchical model of approach and avoidance achievement motivation. J Pers Soc Psychol 72:218-232

Fox JW, Sanford MF, Hong J, Andersen R, Fifth D, Taylor S (2019) Pakage 'effects'. R Package Version 4:1-1 Available at: https:// cran.r-project.org

Giota J (2010) Multidimensional and hierarchical assessment of adolescents' motivation in school. Scand J Educ Res 54(1):83-97. https:// doi.org/10.1080/00313830903488486 
Giota J, Gustafsson JE (2017) Perceived demands of schooling, stress and mental health: changes from grade 6 to grade 9 as a function of gender and cognitive ability. Stress and health: Journal of the International Society for the Investigation of Stress 33(3):253-266. https://doi.org/10.1002/smi.2693

Giota J, Bergh D (2020) Adolescent academic, social and future achievement goal orientations: implications for achievement by gender and parental education. Scand J Educ Res. https://doi.org/10.1080/ 00313831.2020 .1755360

Gustafsson J-E et al. (2010) School, learning and mental health: a systematic review. Kungl. Vetenskapsakademin, Hälsoutskottet [the Royal Swedish Academy of Sciences, health committee], Stockholm

Hagquist C (2008) Psychometric properties of the PsychoSomatic problems scale - a Rasch analysis on adolescent data. Soc Indic Res 86: $511-523$

Hagquist C (2009) Psychosomatic health problems among adolescents in Sweden - are the time trends gender related? Eur J Pub Health 19: $331-336$

Hagquist C (2015) Skolelevers psykiska hälsa [Students' mental health]. In. Nordens Välfärdscenter [Nordic Council of Ministers, Nordic Centre for Welfare and Social Issues],

Hagquist C (2016) Family residency and psychosomatic problems among adolescents in Sweden: the impact of child-parent relations. Scandinavian J Public Health 44:36-46

Hagquist C, Bruce M, Gustavsson JP (2009) Using the Rasch model in nursing research: an introduction and illustrative example. Int J Nurs Stud 46:380-393

Hagquist C, Due P, Torsheim T, Välimaa R (2019) Cross-country comparisons of trends in adolescent psychosomatic symptoms - a Rasch analysis of HBSC data from four Nordic countries. Health Qual Life Outcomes 17:27. https://doi.org/10.1186/s12955-019-1097-x

Huang C (2012) Discrimant and critereon-related validity of achievement goals in predicting academic achievment: a meta-analysis. J Educ Psychol 104:48-73

Kaplan A, Maehr ML (1999) Achievement Goals and Student WellBeing. Contemp Educ Psychol 24:330-358

King RB (2017) Social goals and well-being. J Exp Educ 85:107-125

Landstedt E, Asplund K, Gillander Gådin K (2009) Understanding adolescent mental health: the influence of social processes, doing gender and gendered power relations. Sociol Health Illness 31:962-978

Lee JQ, McInerney DM, Liem GAD, Ortiga YP (2010) The relationship between future goals and achievement goal orientations: an intrinsic-extrinsic motivation perspective. Contemp Educ Psychol 35:264-279. https://doi.org/10.1016/j.cedpsych.2010.04.004

Midgley C et al (1997) Patterns of adaptive learning survey (PALS). University of Michigan, Ann Arbor

OECD (2019) Program for international student assessment (PISA). Results from PISA 2018. Country note Sweden

Potrebny T, Wiium N, Moss-Iversen Lundergård M (2017) Temporal trends in adolescents' self-reported psychosomatic health complaints from 1980-2016: a systematic review and meta-analysis. PLoS One 12:e1888374

Rasch G (1960/1980) Probabilistic Models fore Some Intelligence and Attainment Tests (Copenhagen, Danish Institute for Educational Research). Expanded edition (1980) with foreword and afterword by Benjamin D. Wright. The University of Chicago Press, Chicago

Ringbäck Weitoft G, Rosén M (2005) Is perceiving nervousness and anxiety a predictor of premature mortality and severe morbidity? A longitudinal follow up of the Swedish survey of living conditions. J Epidemiol Community Health 2005:794-798

Schunk DH, Pintrich PR, Meece JL (2008) Motivation in education: theory, research and applications, 3rd edn. Pearson Education, Upper Saddle River, N.J

Senko C (2016) Achivement Goal Theory. A story of early promises, eventual discords, and future possibilities. In: Wentzel K, R., Miele DB (eds) Handbook of Motivation at School. Routledge, New York,

Sideridis GD (2005) Goal orientation, academic achievement, and depression: evidence in favor of a revised goal theory framework. J Educ Psychol 97:366-375. https://doi.org/10.1037/0022-0663.97.3. 366

Socialstyrelsen (2017) Utvecklingen av psykisk ohälsa bland barn och unga vuxna. Till och med 2016 [Trends of mental illness among children and young adults until 2016]. Socialstyrlsen [The National Borad of Health and Welfare], Stockholm

Svensson A (2011) Utvärdering genom uppföljning. Longitudinell individforskning under ett halvsekel [evaluation through follow up. Longitudinal individual research during half a century]. Acta Universitatis Gotoburgensis

Tian L, Yu T, Huebner ES (2017) Achievement goal orientations and adolescents' subjective well-being in school: the mediating roles of academic social comparison directions. Front Psychol 8. https://doi. org/10.3389/fpsyg. 2017.00037

Tuominen-Soini H, Salmela-Aro K, Niemivirta M (2008) Achievement goal orientations and subjective well-being: a person-centred analysis. Learn Instr 18:251-266. https://doi.org/10.1016/j.learninstruc. 2007.05.003

van Geelen SM, Hagquist C (2016) Are the ime trends in adolescent psychosomatic problems related to functional impairment in daily life? A 23-year study among 20,000 15-16 year olds in Sweden. J Psychosom Res 87:50-56

Yi H, Tian L, Huebner SE (2019) Mastery goal orientations and subjective well-being in school among elementary school students: the mediating role of school engagement. Eur J Psychol Educ. https:// doi.org/10.1007/s10212-019-00431-x

Publisher's note Springer Nature remains neutral with regard to jurisdictional claims in published maps and institutional affiliations. 